\title{
Percepción de anomia en población urbana salvadoreña: pesimismo, desconcierto y aislamiento
}

\author{
Perception of Anomie in Salvadoran Urban Population: \\ Pessimism, Bewilderment and Isolation
}

\section{Percepção de anomia na população urbana salvadorenha: pessimismo, perplexidade $e$ isolamento}

\author{
Carlos Iván Orellana \\ Universidad Don Bosco, El Salvador \\ ivan.orellana@udb.edu.sv \\ https://orcid.org/0000-0002-4936-867X
}

\section{Resumen}

La percepción de anomia constituye una expresión de alienación esperable en contextos caracterizados por la exclusión, la incertidumbre vital o la debilidad normativa, tal es el caso de la sociedad salvadoreña actual. En el marco de una investigación por encuesta, se exploró la percepción de anomia en una muestra representativa de habitantes mayores de 15 años de edad del Área Metropolitana de San Salvador (AMSS). La medición de anomia percibida fue desarrollada a partir de la depuración de dos escalas clásicas de anomia que dieron como resultado una escala definitiva compuesta por 13 ítems. La escala obtenida es internamente consistente $(\alpha=.71)$ y cuenta con una clara estructura factorial de tres dimensiones (pesimismo, desconcierto y aislamiento) que en conjunto explicaron $44.20 \%$ de la varianza. Los resultados principales obtenidos evidencian que los niveles generales de anomia percibida son altos en los habitantes del AMSS, aunque son estadísticamente mayores entre aquellos con peor situación socioeconómica e instrucción educativa o entre quienes no trabajan. El constructo general correlaciona con variables de victimización e inseguridad (e. g., se tiene o se quiere tener un arma de fuego para protección) 


\section{Revista Iberoamericana \\ de las Ciencias Sociales y \\ Humanísticas}

ISSN: $2395-7972$

y de cultura política (e. g., ineficacia política), variables que corroboran una asociación entre la anomia percibida y experiencias de amenaza y de distanciamiento social e institucional. En síntesis, se obtuvo un modelo de regresión lineal múltiple constituido por siete variables a partir de los correlatos de inseguridad y cultura política mencionados que explicaron $33 \%$ de la varianza de la percepción de anomia. La discusión resalta el cumplimiento del objetivo exploratorio del estudio y la convergencia entre los hallazgos centrales y los antecedentes teóricos y empíricos encontrados de otras latitudes sobre el tema. Asimismo, el vínculo reforzante que parece existir entre la percepción de anomia y el autoritarismo de derechas, el predictor principal de la percepción de anomia según el modelo de regresión lineal estimado. Las conclusiones sugieren tomar distancia de aproximaciones funcionalistas y acríticas al estudiar el fenómeno, reconocer la necesidad de trascender el carácter exploratorio del estudio, ofrecer algunas líneas generales para futuros esfuerzos investigativos que podrían consolidar la propuesta de medición de percepción de anomia, así como resaltar la relevancia de la subjetividad social y sus consecuencias en la realidad concreta.

Palabras clave: alienación, anomia, autoritarismo, escala, violencia.

\section{Abstract}

The perception of anomie constitutes an expectable alienation expression in contexts characterized by exclusion, vital uncertainty or normative weakness, such as the current Salvadoran society. Within a survey-based research framework, the perception of anomie was explored in a representative sample of older than 15 years of age inhabitants of the San Salvador Metropolitan Area (SSMA). The measurement of perceived anomie developed from the refinement of two classic anomy scales that resulted in a definitive 13-item scale. The obtained scale is internally consistent $(\alpha=.71)$ and has a clear three-dimensional factorial structure (pessimism, bewilderment and isolation) that accounted for $44.20 \%$ of the variance. The main results showed high levels of perception of anomie in SMMA's inhabitants but statistically higher levels among those with worse socioeconomic situation and educational instruction or among those unemployed. The general construct correlates with variables of victimization and insecurity (e.g., gangs are problem in the neighborhood, have or want a firearm for protection) and political culture (e.g., political inefficacy, eroded sense of community), variables that corroborate an association between perceived anomie and experiences of threat and social and institutional detachment. A multiple linear regression model constituted of seven variables was obtained using the insecurity and political culture correlates aforementioned that explained $33 \%$ of the variance of the perception of anomie. The 


\section{Revista Iberoamericana \\ de las Ciencias Sociales y \\ Humanísticas}

ISSN: $2395-7972$

discussion highlights the fulfillment of the exploratory objective of the study and the convergence among the central findings and the theoretical and empirical backgrounds on the subject found elsewhere. Likewise, the reinforcing link that seems to exist between the perception of anomie and the right-wing authoritarianism, the main predictor of the perception of anomie according to the estimated linear regression model. Conclusions suggest taking distance from functionalist and uncritical approaches when studying the phenomena, acknowledge the necessity to transcend the exploratory scope of the study, offer some general suggestions for future investigative endeavors that, in addition, can consolidate the proposed measure of perception of anomie, and highlight the relevance of social subjectivity and its consequences on concrete reality.

Keywords: alienation, anomie, authoritarianism, scale, violence.

\section{Resumo}

A percepção da anomia constitui uma expressão da alienação esperada em contextos caracterizados por exclusão, incerteza vital ou fraqueza regulatória, como é o caso da sociedade salvadorenha de hoje. No âmbito de uma investigação de pesquisa, a percepção de anomia foi explorada em uma amostra representativa de habitantes acima de 15 anos na Área Metropolitana de San Salvador (AMSS). A mensuração da anomia percebida foi desenvolvida a partir da purificação de duas escalas clássicas de anomia que resultaram em uma escala definitiva composta por 13 itens. A escala obtida é internamente consistente $(\alpha=0,71)$ e possui uma estrutura fatorial tridimensional clara (pessimismo, confusão e isolamento) que juntos representam 44,20\% da variância. Os principais resultados obtidos mostram que os níveis gerais de anomia percebida são elevados nos habitantes da AMSS, embora sejam estatisticamente maiores entre aqueles com pior nível socioeconômico e instrução educacional ou entre aqueles que não trabalham. O construto geral se correlaciona com variáveis de vitimização e insegurança (por exemplo, você tem ou deseja ter uma arma de fogo para proteção) e cultura política (por exemplo, ineficiência política), variáveis que corroboram uma associação entre anomia percebida e experiências de ameaças e distanciamento social e institucional. Em resumo, foi obtido um modelo de regressão linear múltipla, composto por sete variáveis, com base nos correlatos de insegurança e cultura política mencionados, que explicaram 33\% da variação na percepção de anomia. A discussão destaca o cumprimento do objetivo exploratório do estudo e a convergência entre os achados centrais e os antecedentes teóricos e empíricos encontrados em outras latitudes sobre o assunto. Da mesma forma, o elo de reforço que parece existir entre a percepção de anomia e o autoritarismo de direitos, o principal 
Revista Iberoamericana

de las Ciencias Sociales y

Humanísticas

ISSN: 2395 - 7972

preditor da percepção de anomia de acordo com o modelo de regressão linear estimado. As conclusões sugerem afastar-se de abordagens funcionalistas e acríticas ao estudar o fenômeno, reconhecendo a necessidade de transcender a natureza exploratória do estudo, oferecendo algumas linhas gerais para futuros esforços de pesquisa que possam consolidar a proposta de medir a percepção de anomia, além de destacar a relevância da subjetividade social e suas consequiências na realidade concreta.

Palavras-chave: alienação, anomia, autoritarismo, escala, violência.

Fecha Recepción: Diciembre 2018

Fecha Aceptación: Julio 2019

\section{Introducción}

El alto nivel de violencia y criminalidad es uno de los rasgos más distintivos de El Salvador contemporáneo. Con tasas de homicidio que rondan las 100 muertes por cada 100000 habitantes, el país es considerado - en ausencia de una guerra formal declarada - como el más peligroso del planeta (Mc Evoy y Hideg, 2017; Programa de las Naciones Unidas para el Desarrollo [PNUD], 2018). Esto se evidencia en distintas formas de criminalidad - robos, hurtos, agresiones, abuso sexual, etc.- que alcanzan cotas epidémicas (Instituto Universitario de Opinión Pública [Iudop], 2014). La violencia en el país ha sido una constante histórica cuya complejidad creciente se ha hecho más evidente en los últimos 30 años, desde la firma de los acuerdos de paz de 1992, los cuales pusieron fin a la guerra y generaron una serie de vertiginosas transformaciones en diferentes esferas de la vida nacional.

En efecto, en el decenio de 1990, la violencia bélica fue dando paso a formas de criminalidad enraizadas en el tejido social, como la "delincuencia común”, la violencia pandilleril o el crimen organizado (Walter, 2018). Desde entonces, en El Salvador también se inauguró una nueva institucionalidad electoral democrática, de seguridad pública y de justicia mientras tenían lugar importantes procesos de modernización (e. g., sofisticación de telecomunicaciones, acceso a nuevas formas de ocio, consumismo). Todo esto se unió a un nuevo modelo económico neoliberal que fue implementado de forma paralela a los cambios sociales y políticos apuntados (Orellana, 2012), los cuales ocasionaron turbulencias relevantes y simultáneas para la vida cotidiana de las personas, con repercusiones que continúan hasta ahora.

Por ejemplo, de manera progresiva, el accionar de las pandillas ha reconfigurado delimitaciones territoriales que regulan las formas de convivencia, el intercambio económico e incluso la participación política (Hernández-Anzora, 2017; Iudop, 2014; Walter, 2018). 


\section{Revista Iberoamericana \\ de las Ciencias Sociales y \\ Humanísticas}

ISSN: 2395 - 7972

Efectivamente, este último ámbito — que entonces provocó la instauración de nuevas rutinas electorales y reglas de juego democrático - acusa hoy el deterioro de la cultura democrática (e. g., menos apoyo a la democracia), antipatía hacia los partidos políticos y desconfianza ciudadana por las instituciones electorales (Córdova Macías, Rodríguez y Zechmeister, 2017; Latinobarómetro, 2017).

El nuevo modelo económico, además de la privatización de instituciones estatales o la dolarización, agravó la desigualdad y la exclusión socioeconómica, incluyendo el rezago social en cuanto a capacidades educativas y tecnológicas, lo que provocó que la inestabilidad laboral y el trabajo informal se consolidaran como las formas de sustento de las grandes mayorías (Departamento de Economía UCA, 2017; Orellana, 2012; PNUD, 2013). Migraciones internas suscitadas por el abandono del campo, así como desastres naturales o la violencia contribuyen a la desestructuración familiar y a engrosar la marginalidad mientras añaden presión a la desordenada urbanización. La migración hacia los Estados Unidos ha sido sostenida como un efecto acumulado de las condiciones descritas, con las readecuaciones culturales, económicas y familiares que tales procesos generan (Programa del Estado de la Nación [PEN], 2016; PNUD, 2013, 2018).

Esta síntesis apretada de algunas facetas de El Salvador de las últimas décadas, así como otros procesos paralelos que tienen lugar (inseguridad, precariedad, aumento de brechas sociales, desarraigo, etc.) y la incidencia de procesos globales signados por la incertidumbre o las rupturas de sentido (e. g., crisis económica, terrorismo, desprestigio de las instituciones tradicionales) permiten presuponer que estamos ante un contexto anómico, es decir, unas circunstancias en las cuales las regulaciones sociales que rigen el comportamiento de los individuos sufren quiebres que pueden derivar en tensiones capaces de conducirlos a incurrir en desviaciones sociales (Agnew y Passas, 1997; Passas, 1997).

La anomia constituye un constructo clásico de la teoría sociológica que, durante más de un siglo, se ha consolidado como una teoría principalmente criminológica, de ahí que la comisión de crímenes de distinta gravedad (Messner y Rosenfeld, 2007) constituya la desviación social concreta de mayor interés de esa teoría. Esto permite afirmar que la existencia de altos niveles de violencia y criminalidad en el país constituye una confirmación suficiente de la presencia sociológica del fenómeno (PNUD, 2009), aunque vale acotar que la percepción de la anomia también remite a una interpretación o construcción intersubjetiva de un estado de la sociedad que, por tanto, puede carecer de corroboración objetiva (Teymoori et al., 2016). 


\section{Revista Iberoamericana de las Ciencias Sociales y Humanísticas}

ISSN: $2395-7972$

Lo anterior significa que la teoría de la anomia cuenta con dimensiones y lecturas macrosociales —el quiebre normativo o la conocida "ausencia de normas" (Durkheim, 1897/2004; Merton, 1964) - y microsociales — tensión o presión que puede conducir a comportamientos desviados (Agnew, 2000) - No obstante, el reconocido cariz criminológico y el continuum macromicro de la teoría de la anomia, así como sus posibilidades teóricas o fenomenológicas son más amplias. Las fracturas normativas que alimentan la desviación social (p. ej., delincuencia) caracterizan tanto a una sociedad anómica como a la fragmentación que padece su tejido social. La anomia, por tanto, también implica otros procesos y expresiones relevantes de corte psicosociológico.

\section{La anomia como fenómeno psicosocial}

La visión criminológica que identifica estados personales resultantes de las presiones que puede experimentar un individuo sometido a un contexto anómico (frustración o rabia, según Agnew, 2000) y que pueden derivar en comportamientos criminales no agotan las interpretaciones de corte psicosocial del fenómeno. Según Passas (1997), la anomia sociológica implica un aspecto actitudinal referido a la tendencia a rechazar los estándares sociales (claro en el descoyuntamiento entre medios y fines sociales de Merton, 1964). Pero, además, la anomia puede ser asociada con la percepción compartida de quiebre social que, entre otras cosas, implica la ruptura del sentido de integración del individuo respecto a la sociedad. En otras palabras, estamos ante una lectura psicosocial, y no meramente psicológica del fenómeno. Tal sentido de distanciamiento social ocurriría, primero, como producto de la imbricación comunicativa y relacional de un individuo en un contexto anómico cuyas esferas de existencia se perciben como fracturadas o excluyentes (e. g., el empleo, la política) y, luego, debido a que entablar vínculos sociales confiables con otros resulta problemático bajo estas circunstancias (e. g., desconfianza interpersonal) (Teymoori, Bastian y Jetten, 2017).

Ahora bien, el inicio de la anomia como tema de discusión psicosocial se produjo en el decenio de 1950, aunque dentro de un vocablo de mayor espectro: alienación. Este concepto puede ser entendido de forma general desde un punto de vista objetivo (macro o social) y subjetivo (micro o individual). En el primer caso, hace referencia a las organizaciones sociales apabullantes o a la separación entre los productos históricos y sus creadores (i. e., lectura tradicional marxista), mientras que la lectura subjetiva del fenómeno alude a la escisión o desarraigo de la persona con respecto a sí misma o a los demás, la comunidad o las instituciones (Nisbet, 1977; Seeman, 1983, 


\section{Revista Iberoamericana \\ de las Ciencias Sociales y \\ Humanísticas}

ISSN: $2395-7972$

1991). En última instancia, se trata de un estado que erosiona la sensación de control individual sobre las relaciones interpersonales, el sentido de los acontecimientos, el resguardo de la comunidad o la relación general de la persona con el orden social (Seeman, 1983).

Diversos autores contemporáneos a la discusión original sobre el tema (Citrin, McClosky, Merrill y Sniderman, 1975; Fischer, 1973; Nachmias, 1974; Seeman, 1983) acuñaron para referirse a la alienación expresiones como las siguientes: carencia de poder, ausencia de normas, cinismo, sinsentido, pesimismo, extrañamiento, rechazo de valores, aislamiento social, retraimiento, protesta social o desconfianza. Sin embargo, el paso del tiempo ha reducido la alienación a seis dimensiones (Fernández Ríos, 1994; Smith y Bohm, 2008):

a. Indefensión (powerlessness): Expectativa de que el comportamiento no se relaciona con los resultados futuros o que no se tiene control sobre los acontecimientos vitales

b. Insignificancia (meaningless): Dificultad para comprender los acontecimientos personales y sociales, lo cual compromete la capacidad de planificación o la habilidad para lograr la dirección existencial

c. Carencia de normas (normlessness): Tendencia a privilegiar comportamientos ilegítimos o socialmente rechazados para alcanzar metas socialmente deseables

d. Aislamiento (isolation): Pobreza de contactos sociales y percepción de rechazo social

e. Autoextrañamiento (self-strangement): Tendencia del individuo a implicarse en actividades que no resultan gratificantes

f. Extrañamiento cultural (cultural strangement): Rechazo o devaluación de creencias y valores comúnmente aceptados por la sociedad.

Smith y Bohm (2008), por su parte, sostienen que en la relación teórica entre alienación y anomia ha predominado una visión restringida que liga a esta última con la dimensión de normlessness (ausencia de normas). A esto, Lytkina (2015) añade la indefensión o la carencia de poder, mientras que otros autores no se refieren a ninguna de las anteriores (Taymoori et al., 2016). Estas divergencias conceptuales dan razón a Legge, Davidov y Schmidt (2008) cuando afirman que la base conceptual y la operacionalización constituyen aspectos relevantes del debate que ocupa el estudio de la anomia como fenómeno psicosocial. En cualquier caso, es claro que las distintas dimensiones de la alienación revisadas muestran con claridad que la alienación siempre depende de los otros, en cuanto a compañía afectiva y material inmediata, pero también en cuanto a encarnación simbólica de grupos, afiliaciones, instituciones, valores y medios compartidos para lograr determinadas metas. Por ello, como manifestación psicosocial, la anomia puede ser 


\section{Revista Iberoamericana de las Ciencias Sociales y Humanísticas}

ISSN: $2395-7972$

comprendida como una expresión de carácter alienante propiciada por un medio (sociológicamente) anómico.

\section{Derivas métricas clásicas y actuales del fenómeno}

Considerando la apuesta teórica y metodológica de sus aportes, y especialmente por el denodado cariz psicosocial de sus propuestas, los trabajos clásicos de Leo Srole, así como los de Herbert McClosky y John Schaar ameritan ser destacados a la hora de abordar los esfuerzos históricos de medición de la percepción de anomia — un debate entre los autores se puede encontrar en McClosky y Schaar (1965a) y Srole (1965)—.

Srole (1956) fue pionero en definir a la anomia como una experiencia individual. Esta aparecería en un continuum sociopsicológico con dos dimensiones: una molar — referida a la variación en el grado de unificación de los sistemas sociales o sus subsistemas- y otra molecular - vinculada con una perspectiva del individuo de encontrarse integrado en los campos de acción de las relaciones interpersonales y de los grupos de referencia-. La relación individuo-sociedad oscilaría entre la eunomia (el ideal de orden social) y la anomia (el polo contrario). Desde esta perspectiva molecular, Srole veía la oportunidad de subsanar dificultades metodológicas y operacionales existentes a través del empleo de métodos de encuestas que permitirían situar a los individuos en el continuum eunomia-anomia.

A lo largo de dicho continuum, según el grado de anomia que se experimenta, las personas pueden llegar a generar un sentido generalizado de "pertenencia con los otros" o, por el contrario, una lectura de "distancia o alienación" respecto de los demás. Srole (1956) alude a la integración/distancia individual con respecto a estructuras sociales tales como los grupos de referencia situados "más allá del propio radio de acción" (p. 711). De esta manera, se busca retratar la peculiaridad de quien se sitúa en el continuum eunomia-anomia como resultado de la acción compleja y "recíproca" de factores sociológicos y psicológicos, presentes y pasados. De manera relevante, Srole hipotetiza que la percepción de la anomia comporta el rechazo hacia exogrupos (outgroups) en general y hacia minorías en particular.

Entendiendo la anomia a nivel subjetivo como una ruptura del sentido individual de "apego" con los otros, con la sociedad, sus ámbitos o sus instituciones, Srole (1956) desarrolló una escala de medición que explora nociones como las siguientes: los líderes de la comunidad son indiferentes o actúan de forma contraria a las necesidades individuales; la percepción de que el mundo es inconstante, caótico y difícil de anticipar; retroceso socioeconómico, es decir, una lectura de que 


\section{Revista Iberoamericana \\ de las Ciencias Sociales y \\ Humanísticas}

ISSN: $2395-7972$

uno o las personas como uno se ven imposibilitadas para colmar las metas materiales trazadas; la carencia de normas y de sentido vital, como la dimensión abiertamente deudora de Durkheim según la cual existe dificultad para internalizar las normas y para encontrar sentido a la vida y, por último, la sensación de aislamiento, del marco social de referencia y apoyo. Srole comprueba que su medición de anomia correlaciona positivamente y con más intensidad con actitudes hostiles hacia minorías en comparación con la relación que presentan estas últimas y la "escala F", conocida en el estudio clásico de la personalidad autoritaria.

Por su parte, McClosky y Schaar (1965b) inician su reflexión sobre la anomia constatando el interés que reciben en su esquema explicativo los estados psicológicos. Los autores tienen por objetivo explorar la relación entre la anomia —o anomy, como se denomina en tanto disposición psicológica - y ciertos estados psicológicos con independencia de aspecto sociales como el estatus social. Sin negar que ciertas condiciones objetivas deriven en anomia, afirman que los "sentimientos anómicos" suelen no ser considerados. Definen este estado como "la sensación de que el mundo y uno mismo están a la deriva, desorientados, faltos de reglas claras y de asideros" (McClosky y Schaar, 1965b, p. 19).

Según McClosky y Schaar (1965b), la anomia se vincula con dimensiones como "aturdimiento" (o "desorientación cognitiva”, según Legge et al., 2008), pesimismo y futilidad política. Asimismo, como correlatos psicológicos de su medición de anomia se encuentran factores cognitivos como la dificultad para aprender o para interpretar correctamente la realidad e incluso misticismo, escasa intelectualidad, baja educación y aquiescencia. En cuanto a factores emocionales, los autores encuentran inflexibilidad (intolerancia a la ambigüedad, rigidez, obsesividad), ansiedad manifiesta, baja "fuerza del ego" (sentido de inadecuación personal y distorsión del autoconcepto: culpa, insatisfacción vital, frustración con el estatus, entre otras) y agresividad (hostilidad, intolerancia, desprecio por los débiles). Por último, relaciones con sistemas de creencias deshumanizantes como el fascismo y la misantropía. La anomia puede ser interpretada como la percepción de desregulación y desorientación vital, lo cual, de fondo, constituye una de tantas formas que puede adoptar una visión desesperanzada de la propia vida y de la comunidad circundante. Una traducción al castellano de las escalas de anomia de Srole y de McClosky y Schaar pueden encontrarse en Rodríguez (2006).

La percepción de anomia en la actualidad se emplea en estudios desarrollados en diversas latitudes en concordancia teórica con su formulación clásica. Por ejemplo, estudios recientes han encontrado que la anomia percibida actúa como predictor estadístico de disposiciones derogatorias 
Revista Iberoamericana

de las Ciencias Sociales y

Humanísticas

ISSN: $2395-7972$

hacia otros, como el autoritarismo de ala derecha o los prejuicios hacia grupos socioeconómicamente desaventajados (Hövermannac, Großac, Zick y Messner, 2015; Orellana, 2018a). Asimismo, que correlaciona positivamente con estados como indefensión colectiva, desesperanza, indicadores de desempleo y desigualdad, mientras que correlaciona negativamente con cohesión social, así como indicadores de control de corrupción, estabilidad social y económica (Teymoori et al., 2016).

Asimismo, correlaciona negativamente con religiosidad y estatus marital, y positivamente con comportamientos criminales en deportistas (Carter y Carter, 2014) o con conducta antisocial y delictiva en jóvenes infractores (Vera Noriega, Bautista, Ramírez y Yáñez, 2012). En el ámbito organizacional, la anomia erosiona el compromiso del trabajador con la empresa y su deseo de permanencia, el autoconcepto profesional y la percepción de apoyo social en el trabajo (Abreu, de Sousa y de Oliveira Fleury, 2018; Fandiño, Souza, Formiga, Menezes y Bentes, 2015). En general, correlaciona negativamente con indicadores de bienestar humano (Blanco y Díaz, 2005; Muratori, Delfino y Zubieta, 2013).

En la actualidad, el abordaje del fenómeno se concreta en intentos de construcción teórica o de medición novedosa, tanto a nivel macro o sociológico (Messner y Rosenfeld, 2007; Messner, Thome y Rosenfeld, 2008; Schoepfer, 2015) como a nivel micro o psicológico (Benbenaste, Etchezahar y Del Río, 2008; Hövermannac et al., 2015; Teymoori et al., 2016). Más allá de actualizaciones y debates sobre el constructo y su medición, las propuestas de Srole y de McClosky y Schaar siguen encontrando eco en estudios contemporáneos, de manera íntegra o con modificaciones, en contextos organizacionales y culturales diferentes, como una aproximación a la percepción de anomia asociada a la existencia de condiciones sociales anómicas (e. g., Blanco y Díaz, 2005, 2006; Carter y Carter, 2007, 2014; Legge et al., 2008; Teymoori et al., 2016). Los trabajos clásicos pueden ser considerados como precursores del intento de aproximación a realidades complejas que exacerban la experiencia de fragmentación social, incertidumbre, bajo sentido de autoeficacia vital, desconfianza hacia las instituciones y que, hace más de medio siglo, iniciaron lo que ahora se concreta en numerosas escalas que han intentado medir expresiones de la díada anomia-alienación (Lytkina, 2015). 
Revista Iberoamericana

de las Ciencias Sociales y

Humanísticas

ISSN: $2395-7972$

\section{Objetivos generales de investigación}

Con el trasfondo de las reflexiones anteriores, se formulan dos grandes objetivos de investigación para el presente trabajo exploratorio. El primero, describir el nivel de anomia percibida en una muestra representativa de habitantes de sectores urbanos del Área Metropolitana de San Salvador (AMSS), El Salvador. En segundo lugar, determinar el vínculo que existe entre la percepción de anomia en relación con variables sociodemográficas, de victimización e inseguridad y de cultura política.

\section{Método}

\section{Participantes}

La muestra estuvo conformada con base en los parámetros poblacionales de las proyecciones de población del año 2010 (Dirección General de Estadística y Censos del Ministerio de Economía [DIGESTYC], 2009). Se contó con una muestra representativa de los habitantes de 15 años en adelante del AMSS, región geoadministrativa heterogénea en términos socioeconómicos, urbana casi en su totalidad y con altos índices de violencia e inseguridad. La muestra fue seleccionada de forma azarosa y su tamaño fue establecido a partir de la presunción del carácter infinito de la población de origen (95\% de confiabilidad (Z), varianza del $50 \%$ (p) y un error muestral (E) inferior a $4.8 \%$ ).

En concreto, participaron 421 habitantes del AMSS de ambos sexos (44.2\% hombres y $55.8 \%$ mujeres $)$ con un promedio de edad de 39.2 años $(D E=17.2)$. Casi la mitad de la muestra (48 \%) se ubicó en un estrato social bajo; más de la tercera parte $(35.4 \%)$ pertenecía a sectores medios y el restante $16.6 \%$ se ubicaba en el sector medio alto o alto. El promedio de ingresos mensuales familiares fue de \$ 528.35 USD ( $D E=\$ 562.72$ USD). En cuanto a la educación formal, $41.1 \%$ había cursado noveno grado como máximo, $28 \%$ tenía cubierto el bachillerato, mientras que el resto (30.9\%) había alcanzado estudios técnicos o superiores. 
Revista Iberoamericana

de las Ciencias Sociales y

Humanísticas

ISSN: $2395-7972$

\section{Instrumento}

La escala de anomia percibida empleada en esta investigación surgió de la fusión y depuración métrica de las escalas clásicas de Srole (1956) y de McClosky y Schaar (1965b). Ambas registran la percepción de que el mundo y uno mismo se encuentran desorientados, carentes de reglas claras y de asideros normativos o relacionales, respecto a personas, grupos o instituciones. En su forma, las escalas fueron traducidas y contextualizadas de forma libre considerando los trabajos originales de los autores, tomando en cuenta la escala ampliada de Srole expuesta por Seeman (1991) y con base en la redacción y traducción de ítems utilizados por Rodríguez (2006).

La validez de contenido de la escala empleada puede darse por sentada al constituir un derivado de las escalas clásicas reconocidas de forma generalizada como medidas de anomia percibida. Sin embargo, la fusión de estas en búsqueda de la medición más sólida posible del constructo, sugería depurar - en primer lugar- el conjunto de ítems de ambas escalas para luego establecer su estructura factorial resultante. Lo primero fue realizado a partir de la revisión del contenido de cada ítem, del análisis de consistencia interna y de análisis factoriales exploratorios aplicados a ambas escalas. Al final se obtuvo una escala de medición de anomia percibida compuesta por 13 ítems cuyos puntajes fueron unificados en una escala de respuesta de 0 a 10 puntos, donde el mayor puntaje significa más percepción de anomia.

Las escalas de Srole y de McClosky y Schaar totalizan 18 ítems, nueve por cada escala. En el proceso de depuración antes descrito, el ítem Los políticos no están realmente interesados en lo que le pasa al salvadoreño común fue eliminado de la escala de Srole. De la escala de McClosky y Schaar se eliminaron los siguientes cuatro ítems: Muchas cosas que eran importantes para nuestros padres se están perdiendo, El problema de hoy es que la mayoría de la gente realmente no cree en nada, Usted se siente frecuentemente incómodo y fuera de lugar y La gente estaba mejor en los tiempos de antes, cuando todos sabían exactamente qué es lo que tenían que hacer.

La consistencia interna de la escala fue satisfactoria $(\alpha=.71)$ según la literatura especializada (Taber, 2017). Asimismo, los resultados del test de Kaiser-Meyer-Olkin (KMO = .78) y los de la prueba de esfericidad de Bartlett $(\chi 2[78]=681.121, p<.001)$ confirmaron la adecuación de los datos para la realización de un análisis factorial exploratorio para determinar la estructura factorial final del constructo. La tabla 1 expone los ítems que finalmente constituyeron la escala de anomia percibida, su procedencia según las escalas originales y su distribución por factores. 


\section{Revista Iberoamericana de las Ciencias Sociales y Humanísticas}

Tabla 1. Origen, enunciado de ítems y distribución factorial de la escala de anomia percibida

\begin{tabular}{|c|c|c|c|c|}
\hline \multirow{2}{*}{$\begin{array}{c}\text { Escala } \\
\text { de } \\
\text { origen }\end{array}$} & \multirow{2}{*}{ Ítems } & \multicolumn{3}{|c|}{ Factores } \\
\hline & & 1 & 2 & 3 \\
\hline & Aislamiento & & & \\
\hline McyS & A otras personas se les hace más fácil decidir qué es lo correcto. & .498 & & \\
\hline Srole & En la actualidad, uno tiene que vivir el día a día y no pensar mucho en el futuro. & .455 & & \\
\hline Srole & Junto a la salud, el dinero es la cosa más importante en la vida. & .626 & & \\
\hline Srole & A veces no queda más que preguntarse si las cosas valen la pena. & 667 & & \\
\hline Srole & $\begin{array}{l}\text { Para hacer dinero no hay maneras correctas o incorrectas, solo formas fáciles o } \\
\text { difíciles. }\end{array}$ & .662 & & \\
\hline & Desconcierto & & & \\
\hline McyS & $\begin{array}{l}\text { En estos días, todo cambia tan rápido que da problema decidir cuáles son las } \\
\text { reglas correctas a seguir. }\end{array}$ & & .556 & \\
\hline McyS & $\begin{array}{l}\text { Es difícil saber qué le va a pasar a uno de un día para otro con el estado de } \\
\text { desorden en que están las cosas. }\end{array}$ & & $\begin{array}{c}.75 \\
2 \\
\end{array}$ & \\
\hline McyS & $\begin{array}{l}\text { Hoy en día lo que escasea es el antiguo tipo de amistades que duraban toda la } \\
\text { vida. }\end{array}$ & & $\begin{array}{c}.64 \\
0\end{array}$ & \\
\hline McyS & $\begin{array}{l}\text { Hoy en día, con las cosas tan inseguras, parece que casi cualquier cosa podría } \\
\text { suceder. }\end{array}$ & & $\begin{array}{c}.56 \\
4 \\
\end{array}$ & \\
\hline & Pesimismo & & & \\
\hline Srole & A pesar de lo que se dice, a mucha de la gente común le está yendo peor. & & & .558 \\
\hline Srole & Es casi injusto traer niños al mundo por como se ve el futuro. & & & .674 \\
\hline Srole & En estos días uno no sabe realmente con quién puede contar. & & & .734 \\
\hline Srole & A la mayoría de la gente no le importa lo que le suceda a los demás. & & & .601 \\
\hline
\end{tabular}

Fuente: Elaboración propia

El análisis factorial exploratorio fue llevado cabo a través del método de extracción de componentes principales y se recurrió a una rotación Varimax. Como se aprecia en la tabla 1, el constructo de anomia percibida obtenido a partir de las escalas clásicas se compone de tres factores claramente delimitados que en conjunto explican $44.20 \%$ de la varianza de los resultados. El factor 1 se conforma de cinco ítems: cuatro provenientes de la escala de Srole y uno de la de McClosky y Schaar, y explica $14.90 \%$ de la varianza de los resultados. El segundo factor alcanza a explicar $14.80 \%$ de la varianza contando con cuatro ítems, todos procedentes de la escala de McClosky y Schaar. Finalmente, el factor tres aglutina $14.50 \%$ de la varianza explicada y la integran cuatro ítems de la escala de Srole.

Considerando la terminología de las investigaciones sobre alienación-anomia y el contenido dominante de los ítems que integran cada factor, el factor 1 ha sido denominado aislamiento, el segundo desconcierto y el tercero pesimismo. Cada subescala de los factores de la anomia percibida 


\section{Revista Iberoamericana \\ de las Ciencias Sociales y \\ Humanísticas}

ISSN: $2395-7972$

es unidimensional (da cuentan de un único factor de base) y alcanzan niveles modestos de consistencia interna según el coeficiente alfa de Cronbach (aislamiento .57; desconcierto .56; y pesimismo .59). En este trabajo se asume que los tres factores de primer orden encontrados de forma empírica pueden ser tratados diferencialmente aunque, en conjunto, constituyen la percepción de anomia en tanto que factor general de segundo orden.

Los análisis de consistencia interna de cada una de las escalas originales de anomia muestran niveles de fiabilidad inferiores al constructo elaborado: la escala de Srole alcanzó un coeficiente alfa de Cronbach de .63 y la de McClosky y Schaar un coeficiente de .69. Asimismo, el constructo obtenido cuenta con el potencial de ser más sofisticado y parsimonioso en términos teóricos debido a su clara estructura tridimensional. Las investigaciones originales como las aplicaciones contemporáneas de las escalas de Srole y de McClosky y Schaar suelen mostrar niveles de consistencia interna moderados o bajos (e. g., Blanco y Díaz, 2005; Muratori, Delfino y Zubieta, 2013), por lo que los indicios de fiabilidad hallados en esta oportunidad convergen con los antecedentes disponibles. La congruencia teórica de las relaciones estadísticas existentes entre la percepción de anomia y otras variables de corte social y político que serán revisadas en los resultados podrán ser interpretadas como indicios de validez de criterio-concurrente.

Las escalas clásicas de anomia administradas fueron incluidas en un cuestionario en formato de encuesta constituido por un total de 117 ítems, mayoritariamente con formato de respuesta cerrada. La encuesta estaba constituida por preguntas y escalas distribuidas en las cinco secciones siguientes: preguntas sociodemográficas (sexo, nivel de estudios, etc.), opiniones sobre la situación del país, victimización e inseguridad, valores y creencias (en esta sección fueron colocadas por separado las escalas clásicas de anomia) y aspectos de cultura política. Las distintas escalas y preguntas fueron distribuidas a lo largo del cuestionario con el fin de contrarrestar la dispersión de la atención, la fatiga o la aquiescencia en las tendencias de respuesta de los entrevistados.

Para cumplir con los objetivos de investigación trazados fueron elegidas entre las preguntas y escalas disponibles en la encuesta algunas de corte sociodemográfico (sexo, edad, estrato social, religión, ocupación y situación económica), otras sobre inseguridad y victimización y unas más sobre cultura política. En la tabla 2 se exponen las variables de victimización e inseguridad, mientras que en la tabla 3 se ofrecen las variables de cultura política elegidas para llevar a cabo los análisis, así como su respectiva operacionalización. 


\section{Revista Iberoamericana de las Ciencias Sociales y Humanísticas}

Tabla 2. Variables de victimización e inseguridad y su operacionalización

\begin{tabular}{|c|c|}
\hline Variables & Operacionalización \\
\hline $\begin{array}{l}\text { Ha pensado en irse del país por temor a } \\
\text { la delincuencia. }\end{array}$ & $1=$ Sí, $0=$ No \\
\hline Ha sido víctima de crimen. & $1=$ Sí, $0=$ No \\
\hline Familiar/amigo ha sido victimizado. & $1=$ Sí, $0=$ No \\
\hline $\begin{array}{l}\text { Vio a una persona asesinada en la calle } \\
\text { en el último año. }\end{array}$ & $1=$ Sí, $0=$ No \\
\hline Arma de fuego para protección & $\begin{array}{l}\text { 1= Tiene o le gustaría tener una, } 0=\text { No tiene ni le gustaría } \\
\text { tener una }\end{array}$ \\
\hline Pandillas son problema en el barrio & $1=$ Mucho/algo, $0=$ Poco/nada \\
\hline Desconfianza interpersonal & $\begin{array}{l}\text { Escala convertida a un rango de } 0-10 \text { puntos que combina } \\
\text { dos ítems: La hipocresía está aumentando en nuestra } \\
\text { sociedad y La mayoría de personas están interesadas en } \\
\text { su propia conveniencia }(\alpha=.69) \text {. }\end{array}$ \\
\hline Prejuicio hacia delincuentes & $\begin{array}{l}\text { Escala convertida a un rango de } 0-10 \text { puntos que combina } \\
\text { cuatro afirmaciones: dos sobre el carácter nato o } \\
\text { patológico del delincuente y dos sobre su supuesta } \\
\text { inferioridad moral }(\alpha=.43) \text {. }\end{array}$ \\
\hline Miedo al delito & $\begin{array}{l}\text { Escala convertida a un rango de } 0-10 \text { puntos que registra } \\
\text { la intensidad del temor ante la posibilidad de sufrir ocho } \\
\text { tipos de delitos (homicidio, robo, abuso sexual, etc.) }(\alpha= \\
.88) \text {. }\end{array}$ \\
\hline
\end{tabular}

Fuente: Elaboración propia

Tabla 3. Variables de cultura política y su operacionalización

\begin{tabular}{|l|l|}
\hline \multicolumn{1}{|c|}{ Variables } & \multicolumn{1}{c|}{ Operacionalización } \\
\hline Confianza institucional & $\begin{array}{l}\text { Escala convertida a un rango de 0-10 puntos que registra el grado } \\
\text { de confianza hacia 14 instituciones sociales (e. g., iglesias) y } \\
\text { políticas (e. g., asamblea legislativa) }(\alpha=.79) .\end{array}$ \\
\hline $\begin{array}{l}\text { Legitimidad (preferencia por } \\
\text { régimen político autoritario). }\end{array}$ & $\begin{array}{l}1=\text { Indiferencia por régimen político/prefiere autoritarismo, } 0= \\
\text { prefiere democracia ante cualquier otra forma de gobierno. }\end{array}$ \\
\hline Interés en política & $0=$ Nada, 1 = Algo, 2 = Poco, 3 = Mucho. \\
\hline $\begin{array}{l}\text { Ineficacia política (Montero, } \\
\text { Gunther y Torcal, 1998) }\end{array}$ & $\begin{array}{l}0=\text { Muy en desacuerdo, 1 = Algo en desacuerdo, 2 = Indeciso, 3 = } \\
\text { Algo de acuerdo, 4 Muy de acuerdo. El ítem mide la percepción } \\
\text { de capacidad para incidir en la política a pesar de su complejidad. }\end{array}$ \\
\hline $\begin{array}{l}\text { Erosión de sentido de } \\
\text { comunidad }\end{array}$ & $\begin{array}{l}\text { Escala convertida a un rango de 0-10 puntos que combina tres } \\
\text { ítems: Nuestros líderes no saben lo que hacen, No hay acuerdo } \\
\text { social sobre temas importantes y urgentes y La situación que } \\
\text { vivimos hace pensar que la protesta social crecerá ( } \alpha=.55) .\end{array}$ \\
\hline $\begin{array}{l}\text { Autoritarismo de derechas } \\
\text { (Orellana 2018b) }\end{array}$ & $\begin{array}{l}\text { Escala tridimensional de 0-10 puntos: sumisión autoritaria, } \\
\text { agresión autoritaria y convencionalismo ( } \alpha=.83) .\end{array}$ \\
\hline
\end{tabular}

Fuente: Elaboración propia 
Revista Iberoamericana

de las Ciencias Sociales y Humanísticas

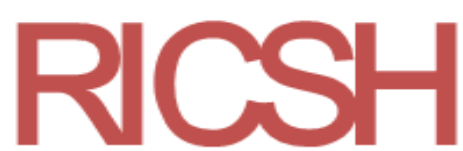

ISSN: 2395 - 7972

\section{Procedimiento}

El levantamiento de datos tuvo lugar en 2010. El muestreo empleado en su momento fue denominado como probabilístico estratificado, a través de selección sistemática de elementos muestrales (Bordens y Abott, 1999; Hernández-Sampieri, Fernández-Collado y Baptista Lucio, 2006). Este procedimiento, para procurar la dispersión y la representatividad muestral, implementa un mecanismo poliétapico en el que las unidades muestrales son elegidas de manera aleatoria dentro de la región de interés y con base en características de inclusión particulares (ambos sexos, edad, procedencia socioeconómica diversa, etc.). Las encuestas fueron administradas por un equipo de especialistas entrenados. El consentimiento informado, la confidencialidad, la debida identificación del encuestador y la posibilidad de contactar a los investigadores ante dudas de seguridad o de corte procedimental constituyeron parte del protocolo ético de la aplicación de cada encuesta.

\section{Resultados}

A partir de los objetivos de investigación trazados, esta sección se divide en dos: en la primera se describen los resultados de la percepción de anomia y sus dimensiones en relación con las características sociodemográficas de la muestra. En la segunda se presentan correlaciones entre el constructo y las variables de victimización e inseguridad y de cultura política para luego mostrar un modelo de regresión que permita identificar predictores estadísticos de la anomia percibida en la población salvadoreña que habita el AMSS. Todas las escalas principales y secundarias empleadas en los análisis fueron convertidas a puntajes que oscilan entre 0 y 10 mediante el programa SPSS, versión 24.

En la tabla 4 se enseñan los promedios del constructo de percepción de anomia, así como sus dimensiones (desconcierto, pesimismo y aislamiento) en relación con algunas características sociodemográficas de la muestra. 
Revista Iberoamericana

de las Ciencias Sociales y

Humanísticas

ISSN: 2395 - 7972

Tabla 4. Medias y desviaciones de la escala de anomia y sus dimensiones según variables sociodemográficas

\begin{tabular}{|l|c|c|c|c|}
\hline \multicolumn{1}{|c|}{ Variables } & Anomia & Desconcierto & Pesimismo & Aislamiento \\
\hline TODOS/AS & M(DE) & M(DE) & M(DE) & M(DE) \\
\hline Sexo & $\mathbf{7 . 2 ( 1 . 6 )}$ & $\mathbf{8 . 4 ( 1 . 9 )}$ & $\mathbf{7 . 5 ( 2 . 1 )}$ & $\mathbf{5 . 7 ( 2 . 4 )}$ \\
\hline Masculino & & & & \\
\hline Femenino & $7.2(1.5)$ & $8.4(1.8)$ & $7.4(2.0)$ & $5.7(2.4)$ \\
\hline Edad & $7.2(1.7)$ & $8.4(1.9)$ & $7.5(2.2)$ & $5.6(2.4)$ \\
\hline 15 a 34 años & & & & \\
\hline Más de 35 años & $7.3(1.5)$ & $8.5(1.8)$ & $7.6(1.9)$ & $5.7(2.3)$ \\
\hline Nivel educativo & $7.1(1.6)$ & $8.3(1.9)$ & $7.3(2.2)$ & $5.7(2.4)$ \\
\hline 0-9 años de escolaridad & & & & \\
\hline Bachillerato & $7.4(1.6)$ & $8.4(1.9)$ & $7.6(2.1)$ & $6.2(2.3)$ \\
\hline Técnico/universitario & $7.2(1.6)$ & $8.5(1.7)$ & $7.5(2.1)$ & $5.7(2.4)$ \\
\hline Estrato social & $6.9(1.5)^{*}$ & $8.3(1.9)$ & $7.5(2.0)$ & $4.9(2.3)^{*}$ \\
\hline Alto/medio alto & & & & \\
\hline Medio & $6.6(1.7)$ & $7.9(2.2)$ & $6.8(2.2)$ & $4.9(2.6)$ \\
\hline Bajo & $7.3(1.6)$ & $8.5(1.8)$ & $7.7(2.1)$ & $5.7(2.2)$ \\
\hline Religión & $7.3(1.5)^{*}$ & $8.5(1.7)^{*}$ & $7.5(2.0)^{*}$ & $5.9(2.3)^{*}$ \\
\hline Ninguna/otra & & & & \\
\hline Católica & $7.4(1.6)$ & $8.4(1.9)$ & $7.8(1.9)$ & $5.9(2.4)$ \\
\hline Evangélica & $7.3(1.6)$ & $8.5(1.8)$ & $7.5(2.1)$ & $5.7(2.4)$ \\
\hline Ocupación & $7.1(1.5)$ & $8.3(2.0)$ & $7.3(2.1)$ & $5.6(2.3)$ \\
\hline Trabaja o estudia & & & & \\
\hline No trabaja & $7.0(1.5)$ & $8.3(1.8)$ & $7.3(1.9)$ & $5.4(2.4)$ \\
\hline Situación económica & $7.4(1.6)^{*}$ & $8.5(1.9)$ & $7.6(2.2)$ & $6.0(2.3)^{*}$ \\
\hline Ha mejorado/sigue igual & $6.9(1.7)$ & $8.0(2.0)$ & $7.1(2.2)$ & $5.5(2.4)$ \\
\hline Ha empeorado & $7.3(1.5)^{*}$ & $8.5(1.8)^{*}$ & $7.5(2.0)$ & $5.7(2.3)$ \\
\hline Nota: * $p<.05$. & & & & \\
\hline & & & & \\
\hline & & & & \\
\hline
\end{tabular}

Fuente: Elaboración propia

La tabla 4 muestra que el nivel de anomia percibida es alto en la población del AMSS $(M=7.2, D E=1.6)$. El nivel de aislamiento puede considerarse moderado $(M=5.7, D E=2.4)$, pero el pesimismo $(M=7.5, D E=2.1)$ y sobre todo el desconcierto $(M=8.4, D E=1.9)$ alcanzan altos niveles; incluso ambas dimensiones tienen una moda de 10, mayor puntaje posible en la escala. En términos generales, los niveles descritos se mantienen a lo largo de las variable sociodemográficas registradas en la encuesta, pero no existen diferencias estadísticas entre la anomia percibida o sus dimensiones respecto al sexo, edad o religión.

Sí existen, en cambio, diferencias significativas entre las medias de anomia percibida ( $F(2$, $418)=4.531, p=.011)$ y de aislamiento $(F(2,418)=11.033, p<.001)$ de acuerdo con el nivel educativo. Quienes cuentan con nueve años de escolaridad o menos presentan un promedio de anomia percibida significativamente mayor $(M=7.4, D E=1.6)$ en comparación con quienes 


\section{Revista Iberoamericana \\ de las Ciencias Sociales y Humanísticas}

ISSN: $2395-7972$

cuentan con educación técnica o universitaria $(M=6.9, D E=1.5)$, pero ambas categorías no difieren en sus promedios respecto al de quienes tienen bachillerato. Los promedios de aislamiento son estadísticamente diferentes entre las tres categorías de nivel de estudios.

Los tres estratos sociales considerados presentan diferencias significativas entre ellos frente a la percepción de anomia y sus dimensiones (Anomia: $F(2,418)=6.893, p=.001$. Dimensiones: pesimismo, $F(2,418)=4.280, p=.014 ;$ desconcierto, $F(2,418)=3.636, p=.027$; aislamiento, $F$ $(2,418)=4.234, p=.015)$. Como se aprecia en la tabla 4 , en todos los casos, el estrato social alto/medio alto cuenta con promedios menores de los constructos considerados en comparación con los de los estratos medio y bajo, pero estos dos últimos no difieren estadísticamente entre sí en cuanto a la percepción de anomia o alguna de sus dimensiones. Por otra parte, quienes no trabajan manifiestan un nivel estadísticamente más alto de percepción de anomia $(t(419)=-2.369, p=.018)$ y de aislamiento $(t(419)=-2.952, p=.003)$ que quienes estudian o trabajan. El promedio de percepción de anomia $(t(419)=2.045, p=.042)$ y de desconcierto $(t(419)=2.124, p=.034)$ también es significativamente mayor entre quienes consideraron que la situación económica había empeorado frente a quienes opinaron que había mejorado o que no había cambiado en el momento de contestar la encuesta.

Como cabría esperar, las dimensiones de anomia percibida correlacionan positivamente entre sí, de tal manera que el pesimismo incrementa en la medida en que lo hace el aislamiento $(r=$ $.39, p<.01)$ y el desconcierto $(r=.41, p<.01)$, y esta última incrementa concomitantemente con el aislamiento $(r=.24, p<.01)$.

Por otra parte, las tablas 5 y 6 presentan, respectivamente, correlaciones entre la percepción de anomia y variables de victimización e inseguridad, y entre aquella y variables de cultura política. La percepción de anomia correlaciona positivamente con haber visto a una persona asesinada en la calle, si se cuenta o se quiere un arma de fuego para protección, según se percibe a las pandillas como un problema en el barrio, conforme incrementa la desconfianza interpersonal y el miedo al delito. Respecto a las variables de cultura política, la anomia percibida correlaciona positivamente con mostrar indiferencia o preferir un régimen autoritario, con el sentido de ineficacia política y con la erosión del sentido de comunidad. 


\section{Revista Iberoamericana de las Ciencias Sociales y Humanísticas}

ISSN: $2395-7972$

Tabla 5. Correlaciones entre anomia percibida y variables de victimización e inseguridad

\begin{tabular}{|c|l|l|l|l|l|l|l|l|l|l|l|}
\hline & & $(1)$ & $(2)$ & $(3)$ & $(4)$ & $(5)$ & $(6)$ & $(7)$ & $(8)$ & $(9)$ & $(10)$ \\
\hline$(1)$ & Anomia percibida & & & & & & & & & & \\
\hline$(2)$ & $\begin{array}{l}\text { Ha pensado irse del país por } \\
\text { temor a la delincuencia }\end{array}$ & .08 & & & & & & & & \\
\hline$(3)$ & Ha sido victimizado & .07 & $.13^{* *}$ & & & & & & & & \\
\hline$(4)$ & Familiar/amigo fue victimizado & .01 & $.16^{* *}$ & $.26^{* *}$ & & & & & & & \\
\hline$(5)$ & $\begin{array}{l}\text { Vio a una persona asesinada en } \\
\text { la calle }\end{array}$ & $.13^{*}$ & $.23^{* *}$ & $.19^{* *}$ & $.29 * *$ & & & & & & \\
\hline$(6)$ & $\begin{array}{l}\text { Tiene/gustaría tener arma de } \\
\text { fuego para protección }\end{array}$ & $.17^{* *}$ & $.15^{* *}$ & .09 & $.10^{*}$ & $.10^{*}$ & & & & & \\
\hline$(7)$ & $\begin{array}{l}\text { Pandillas son problema en } \\
\text { barrio }\end{array}$ & $.21^{* *}$ & $.17^{* *}$ & $.13^{*}$ & $.16^{* *}$ & $.30^{* *}$ & .08 & & & \\
\hline$(8)$ & Desconfianza interpersonal & $.33^{* *}$ & .03 & .02 & .09 & $.10^{*}$ & .02 & .09 & & \\
\hline$(9)$ & Prejuicios hacia delincuentes & $.28^{* *}$ & .02 & .03 & .01 & .05 & $.17 * *$ & .02 & $.22^{* *}$ & \\
\hline$(10)$ & Miedo al delito & $.12^{*}$ & $.22^{* *}$ & $.15^{* *}$ & $.20^{* *}$ & $.20^{* *}$ & .05 & $.24 * *$ & -.10 & .03 & \\
\hline Nota: $*$ p $p .05, * * p<.01$. & & & & & \\
\hline
\end{tabular}

Fuente: Elaboración propia

Tabla 6. Correlaciones entre anomia percibida y variables de cultura política

\begin{tabular}{|l|l|l|l|l|l|l|l|l|}
\hline & & $(1)$ & $(2)$ & $(3)$ & $(4)$ & $(5)$ & $(6)$ & $(7)$ \\
\hline$(1)$ & Anomia percibida & & & & & & & \\
\hline$(2)$ & Confianza institucional & -.08 & & & & & & \\
\hline$(3)$ & Indiferente/prefiere régimen autoritario & $.10^{*}$ & -.09 & & & & & \\
\hline$(4)$ & Interés en política & -.08 & $23^{* *}$ & $-.11^{*}$ & & & & \\
\hline$(5)$ & Ineficacia política & $.26^{* *}$ & -.01 & .07 & $-.22^{* *}$ & & & \\
\hline$(6)$ & Erosión de sentido de comunidad & $.29^{* *}$ &.$- .15^{* *}$ & -.04 & -.02 & $.12^{*}$ & & \\
\hline$(7)$ & Autoritarismo de derechas & $.41^{* *}$ & .07 & $.16^{* *}$ & $-.17^{* *}$ & $.22^{* *}$ & .07 & \\
\hline Nota: $* p<.05, * * p<.01$. & & $\mathrm{X}$ & $\mathrm{X}$ \\
\hline
\end{tabular}

Fuente: Elaboración propia

Finalmente, se recurrió a un modelo de regresión lineal múltiple en el que la percepción de anomia fungió como variable dependiente, mientras que las variables sociodemográficas, las de victimización e inseguridad y las de cultura política que resultaron estar relacionadas estadísticamente en los análisis bivariados constituyeron variables predictoras. En la tabla 7 se puede apreciar un modelo estadísticamente significativo conformado por siete variables que en conjunto explican un tercio de la varianza $\left(R^{2} A j .=0.331\right)$ de la percepción de anomia de los habitantes del AMSS. Las variables que resultaron ser predictoras de la anomia percibida fueron el autoritarismo de derechas, la erosión del sentido de comunidad, la desconfianza interpersonal, la pertenencia a estratos sociales socioeconómicamente desfavorecidos, el prejuicio hacia los delincuentes, no trabajar por distintos motivos y experimentar ineficacia política. 


\section{Revista Iberoamericana de las Ciencias Sociales y Humanísticas}

Tabla 7. Modelo de regresión lineal múltiple para la escala percepción de anomia

\begin{tabular}{|c|c|c|c|c|c|}
\hline & B & Error & B & $\mathbf{T}$ & Sig. \\
\hline Constante & 2.132 & .427 & & 4.996 & .0001 \\
\hline Autoritarismo de derechas & .274 & .042 & .299 & 6.531 & .0001 \\
\hline Erosión de sentido de comunidad & .131 & .028 & .205 & 4.615 & .0001 \\
\hline Desconfianza interpersonal & .134 & .030 & .200 & 4.426 & .0001 \\
\hline Estrato social descendente & .202 & .071 & .120 & 2.843 & .005 \\
\hline Prejuicio hacia los delincuentes & .085 & .033 & .116 & 2.568 & .011 \\
\hline No trabaja por distintos motivos & -.337 & .131 & -.107 & -2.577 & .010 \\
\hline Ineficacia política & .099 & .041 & .101 & 2.391 & .017 \\
\hline \multicolumn{6}{|c|}{$[F(7,397)=29.560, p<.001] R^{2}=0.343, R^{2}$ Ajustado $=0.331$} \\
\hline \multicolumn{6}{|c|}{$\begin{array}{l}\text { Nota: Fue aplicado el método por pasos (stepwise). Las variables independientes del modelo han sido } \\
\text { ordenadas a partir del peso del coeficiente beta estandarizado. La operacio } \\
\text { nalización de variables coincide con lo expuesto en las tablas } 2,3 \text { y } 4 \text {, con excepción de la variable } \\
\text { estrato social, pues aquí responde a la codificación siguiente: } 1 \text { = Alto, } 2=\text { Medio alto, } 3=\text { Medio } \\
\text { bajo, } 4 \text { = Obrero, } 5 \text { = Marginal. }\end{array}$} \\
\hline
\end{tabular}

Fuente: Elaboración propia

\section{Discusión}

La anomia percibida constituye un derivado subjetivo de la vida social que se desarrolla en contextos anómicos, como la sociedad salvadoreña contemporánea. En esta, para la gran mayoría de la población, rige la exclusión de esferas de ciudadanía (e. g., empleo, educación, salud), así como el riesgo permanente de la violencia y la criminalidad. En estas condiciones, los vínculos humanos se ven obligados a gestionar de manera reiterada la convivencia cotidiana a través de la flexibilización, la producción o la violación de códigos formales e informales, lo que no excluye la implementación de códigos emergentes que facultan a propios y a extraños a recurrir a la violencia.

Los resultados obtenidos ponen de manifiesto que la percepción de anomia constituye una realidad generalizada entre los habitantes del AMSS. El cumplimiento de los objetivos de investigación no dejan lugar a dudas: los habitantes urbanos mayores de quince años del AMSS experimentan altos niveles de percepción de anomia (y más altos aún en el caso de algunas de sus dimensiones). Pero a partir de los análisis bivariados realizados (ver tabla 2), cabe afirmar que la percepción de anomia o de algunas de sus dimensiones es más acusada en la medida en que se desciende en la escala socioeconómica, que se cuenta con menor escolaridad, no se trabaja por distintas razones o se experimenta el empeoramiento de la situación económica. Es decir, en el caso de los habitantes del AMSS, la anomia percibida parece responder especialmente a condiciones de desventaja y exclusión socioeconómica, donde el día a día resulta más arduo y conforme se asiste a los acontecimientos de la vida nacional desde los márgenes de la sociedad. 


\section{Revista Iberoamericana \\ de las Ciencias Sociales y \\ Humanísticas}

ISSN: $2395-7972$

Los resultados obtenidos son consistentes con los encontrados en la literatura disponible. La percepción de anomia se revela como una expresión de alienación, distanciamiento y dificultad del individuo para hacer inteligible su entorno social (Legge et al., 2008; Passas, 1997; Seeman, 1983). Por ende, los indicios sociodemográficos y los correlatos identificados, así como los de victimización e inseguridad - haber visto a una persona asesinada en la calle, desconfiar de los demás, etc. (ver tabla 5) - y los de cultura política — percibirse superado por la complejidad de la política o que el sentido de comunidad está quebrado, etc. (ver tabla 6) - son coherentes con condiciones de insatisfacción vital, de lecturas entreveradas de perplejidad ante los acontecimientos, de desmoralización ante el intercambio con otros, así como actitudes defensivas, miedo, desconfianza hacia la cosa pública y la democracia o interpretaciones de ruptura del orden social vigente (Blanco y Díaz, 2005; Legge et al., 2008; Muratori et al., 2013; Teymoori et al., 2016).

Asimismo, debe ser resaltado que el cariz psicosocial que implica la fundamentación teórica que subyace en el constructo percepción de anomia nunca se traduce en una interpretación psicologista del fenómeno. Así lo demuestran los vínculos analíticos existentes con la lectura sociológica del fenómeno, su relación con aspectos de contexto (e. g., violencia, exclusión) o al considerar correlatos que lejos de enfrascarse en variables estrictamente psicológicas, consideran condiciones sociomateriales (e. g., situación económica), calidad de vínculos humanos (e. g., confianza interpersonal) o dimensiones de psicología política o de cultura política (e. g., ineficacia política, erosión del sentido de comunidad).

De hecho, en cuanto al factor cultura política, trabajos clásicos y contemporáneos coinciden en que la anomia percibida advierte y se relaciona con la existencia de tendencias discriminatorias y antidemocráticas (e. g., Hövermannac et al., 2015; Srole, 1956). Por ello, es relevante haber encontrado correlatos como la indiferencia por el régimen político o la preferencia por uno de corte autoritario, o que el principal predictor de anomia percibida en el modelo de regresión obtenido sea el autoritarismo de derechas, lo cual se cumple también en la dirección contraria (Orellana, 2018a). En otras palabras, al menos en el país, y considerando que en un modelo siempre existen más variables explicativas, cabe sostener que la relación entre autoritarismo de derechas (convencionalismo, punitividad y complacencia con el orden establecido) y la percepción de anomia (aislamiento, desconcierto y pesimismo) demanda una dinámica de fortalecimiento mutuo que tiene lugar en el marco de una realidad esencialmente precaria, violenta y normativamente laxa, como la de la sociedad salvadoreña. 


\section{Revista Iberoamericana de las Ciencias Sociales y Humanísticas}

ISSN: $2395-7972$

En este escenario propicio, el autoritarismo se manifiesta como rigidez endogrupal, hostilidad hacia otros diferentes y fortalecimiento de cosmovisiones tradicionales (Orellana, 2018a, 2018b), mientras que la anomia, como un espejo perverso, refleja retraimiento ante el estado de cosas, desilusión y perplejidad ante el convencimiento del quiebre social y "pérdida de valores" (de lo cual ciertos grupos sociales son responsables de todo ello). Se podría decir que la percepción de anomia ratifica al individuo autoritario que hay razones para temer, y el autoritario teme $-\mathrm{y}$ buscará defenderse de - los insistentes temores que la anomia le confirma.

Estos resultados son plenamente compatibles con las reflexiones recientes de Teymoori et al. (2017, p. 9), quienes sostienen que la percepción de anomia puede derivar en una "contracción" del "self personal y social", que deriva en autoritarismo o tribalismo. Es decir, tendencias que si bien devuelven sensación de control sobre las propias circunstancias al engrosar los muros simbólicos (e. g., estigmatización) que señalan y excluyen a otros considerados como amenazas, al tiempo que se adoptan terminan reforzando la convicción compartida de quiebre social anómico y las mismas orientaciones sociales antidemocráticas alimentadas por este. Es un círculo vicioso que fortalece la anomia objetiva y la percibida y sus implicaciones, un proceso de erosión gradual del tejido social, el respeto por las normas y la convivencia ciudadana.

El modelo conseguido da cuenta de un importante $33 \%$ de la varianza de la anomia percibida (ver tabla 7). Las variables incluidas en el modelo de regresión igualmente son coherentes con la teoría de la anomia percibida al sugerir vinculaciones del constructo con tendencias discriminatorias (prejuicio hacia delincuentes, autoritarismo de derechas), fragmentación social y política (erosión del sentido de comunidad, desconfianza interpersonal e ineficacia política) y situación de exclusión social (no trabajar, pertenecer a un estrato social más bajo).

A partir de la consistencia interna adecuada, la clara estructura factorial y los correlatos teóricamente coherentes encontrados, se puede afirmar que la escala construida a partir de las escalas clásicas de Srole (1956) y McClosky y Schaar (1965b) cuenta con indicios suficientes para ser empelada como un instrumento válido y confiable para el estudio de la anomia percibida en contextos considerados como anómicos. Para efectos de clarificación conceptual, de forma provisional y general, la dimensión aislamiento podría ser comprendida como la evitación del intercambio con otros a través del confinamiento, la indiferencia, la búsqueda de anonimato o la disminución o resistencia a la interacción y la asociación con otros. El desconcierto consistiría en la dificultad para realizar una lectura inteligible o confiable de las demandas y expectativas propias de la interacción con los demás o con ámbitos del entorno circundante (e. g., noticias, política). 


\section{Revista Iberoamericana \\ de las Ciencias Sociales y \\ Humanísticas}

ISSN: $2395-7972$

Finalmente, el pesimismo se referiría a la tendencia a esperar el peor resultado posible, no esperar nada o desconfiar del curso de los acontecimientos o de las propias acciones y esfuerzos.

\section{Conclusiones}

Intencionalmente se han esquivado reflexiones y debates teóricos relevantes referidos al fenómeno y a la teoría de la anomia debido a la principalidad otorgada a los datos. Debe ser reiterado, por ejemplo, que lejos de posturas funcionalistas u homeostáticas (usualmente asociadas a la obra de Durkheim), en este trabajo se asume la preponderancia de procesos y de realidades inestables que desafían cualquier idea de mecanicismo ingenuo con base en la supuestamente deseable integración social (en tanto que proceso paralelo o contrapuesto a la anomia). El Salvador es un contexto conflictivo donde la integración social de grandes mayorías, si acaso ocurre, es necesariamente paradójica al ocurrir la mayoría de las veces desde posiciones de exclusión social para persistir en ellas o por requerir esfuerzos adaptativos a condiciones violentas o precarias (e. g., vivir en territorios controlados por pandillas, informalidad laboral). Quiere decir que la desadaptación a una realidad como la salvadoreña - a su idiosincrasia informal, su violencia ubicua, su debilidad institucional, su convencionalismo mojigato-, en realidad, puede implicar una forma de lúcida resistencia.

Por otra parte, haber contado con una muestra representativa confiere relevancia empírica y social al presente trabajo, pues no existen precedentes en el país y se desconocen esfuerzos similares, al menos en el istmo centroamericano. Asimismo, tampoco se conocen indagaciones en el contexto latinoamericano con poblaciones reales que corroboren empíricamente el vínculo existente entre tendencias anómicas y autoritarias que resaltan las investigaciones más recientes. Estos aspectos, por cierto, deberían contribuir a disipar cualquier duda sobre la vigencia de los datos presentados, pues la reflexión de base, la medición, los resultados obtenidos y la discusión que el tema suscita son plenamente vigentes dadas las tendencias investigativas actuales del fenómeno y sobre todo la realidad inamovible de un país como El Salvador.

No obstante, igualmente cabe señalar limitantes del trabajo y algunas recomendaciones. El camino a seguir, por ejemplo, remite a superar la limitante general de su carácter exploratorio para avanzar en la profundización teórica del fenómeno y en la confirmación de la calidad métrica del instrumento utilizado. En términos teóricos y analíticos, cabría complejizar la fundamentación y la interpretación aquí sugerida de que la sociedad salvadoreña —o sociedades similares, e. g., el triángulo norte centroamericano- constituye un contexto anómico. Se vuelve necesario, por ende, 


\section{Revista Iberoamericana \\ de las Ciencias Sociales y Humanísticas}

ISSN: 2395 - 7972

el desarrollo de investigaciones que busquen vínculos explicativos teóricamente relevantes y creativos.

Asimismo, algunas posibilidades empíricas para proseguir con el estudio de la anomia percibida pueden enfocarse en la búsqueda de vínculos con realidades como las siguientes: expresiones de incertidumbre vital (e. g., indefensión, ansiedad, inseguridad ciudadana), tendencias antisociales (e. g., consumo de sustancias, delincuencia, corrupción), hostilidad hacia grupos minoritarios (e. g., personas LGTBI, migrantes), calidad de las relaciones en un grupo (e. g., organizaciones, comunidades), fidelidad hacia proyectos colectivos (e. g., movimientos, partidos políticos) o vinculación o distanciamiento del individuo con esferas sociales o políticas de integración (familia, empleo o participación política). Es decir, problemas que actualmente asolan a las sociedades latinoamericanas en general y particularmente a las de la parte norte de mesoamérica.

En última instancia, este artículo trata sobre un derivado perceptual fruto de ciertas condiciones peculiares de vida social, que a su vez impacta y refuerza esas mismas condiciones vitales. Los "hechos sociales subjetivos" (percepciones, actitudes, creencias, etc.) dicen algo de la realidad en la que estos tienen lugar y acarrean consecuencias de interés para las ciencias sociales (e. g., solidaridad o desprecio hacia otros, afiliación o rechazo a proyectos colectivos y políticos). En este sentido, la percepción de anomia en el país constituye la confirmación de la lucha cotidiana de una población mayoritariamente sometida a condiciones difíciles, cambiantes y peligrosas, por dar sentido a un proyecto de sociedad que, a pesar de haber experimentado importantes transformaciones en las últimas décadas, acusa añejos resquebrajamientos provocados por el efecto acumulativo de la desigualdad y la exclusión, la persistente migración, la suspicacia ciudadana hacia la política o la imperecedera afición por la depredación mutua. 
Revista Iberoamericana

de las Ciencias Sociales y

Humanísticas

ISSN: $2395-7972$

\section{Referencias}

Abreu, E., de Sousa, M. A. y de Oliveira Fleury, L. F. (2018). A influência da anomia e do comprometimento organizacional sobre a intenção de rotatividade em organizações. Actualidades en Psicología, 32(125), 51-69. Doi: 10.15517/ap.v32i125.30341

Agnew, R. (2000). The Contribution of Social-Psychological Strain Theory to the Explanation of Crime and Delinquency. In Adler, F. y Laufer, W. S. (eds.), The legacy of anomie theory ( $2^{\text {th }}$ reimp.) (pp. 113-138). New Brunswick y Londres: Transaction Publisher.

Agnew, R. and Passas, N. (1997). Introduction. In Passas, N. and Agnew, R. (eds.), The future of the anomie theory (pp.1-26). Boston: Northeastern University Press.

Benbenaste, N., Etchezahar, E. y Del Río, M. (2008). Psicología de la anomia. Suma Psicológica UST, 5(2), 63-74.

Blanco, A. y Díaz, D. (2005). El bienestar social: su concepto y medición. Psicothema, 17(4), 582589.

Blanco, A. y Díaz, D (2006). Orden social y salud mental: una aproximación desde el bienestar social. Clínica y Salud, 17(1), 7-29.

Bordens, K. S. and Abott, B. B. (1999). Research design and methods: process approach (4 ${ }^{\text {th }}$ ed.). Mountain View: Mayfield Publishing Company.

Carter, E. M. and Carter, M. V. (2007). A social psychological analysis of anomie among National Football League Players. International Review for the Sociology of Sport, 42(3), 243-270. Doi: $10.1177 / 1012690207088110$

Carter, E. and Carter, M. (2014). Anomie, Deviance, and the Religious Factor: Data from 104 NFL Players. Journal of Sociology and Social Work, 2(2), 135-144. Doi: 10.15640/jssw.v2n2a8

Citrin, J., McClosky, H., Merrill, J. and Sniderman, P. M. (1975). Personal and political sources of political alienation. British Journal of Political Science, 5(1), 1-31. Doi: $10.1017 / \mathrm{S} 0007123400008024$

Córdova Macías, R., Rodríguez, M. y Zechmeister, E. J. (2017). Cultura política de la democracia en El Salvador y en las Américas, 2016/17: un estudio comparado sobre democracia y gobernabilidad. Recuperado de https://www.vanderbilt.edu/lapop/el-salvador.php.

Departamento de Economía UCA (2017). Análisis Socioeconómico de El Salvador, año 2017. San Salvador: UCA. Recuperado de http://www.uca.edu.sv/economia/wpcontent/uploads/ASES-a\%C3\%B1o2017_VW.pdf. 
Revista Iberoamericana

de las Ciencias Sociales y

Humanísticas

ISSN: 2395 - 7972

Dirección General de Estadística y Censos [DIGESTYC] (2009). República de El Salvador. Estimaciones y proyecciones de la población 1950-2050. San Salvador: MINEC, UNFPA y CELADE. Recuperado de http://www. censos.gob.sv.

Durkheim, E. (1897/2004). El suicidio. México: Grupo Editorial Tomo.

Fandiño, A., Souza, M. A., Formiga, N., Menezes, R. and Bentes, S. R. (2015). Organizational anomie, professional self-concept and organizational support perception: theoretical model evidences for management. International Journal of Business and Social Science, 11, 1-10. Retrieved from https://repositorio.iscte-iul.pt/handle/10071/11704.

Fernández Ríos, L. (1994). Manual de psicología preventiva. Madrid: Siglo XXI.

Fischer, C. S. (1973). On urban alienations and anomie: Powerlessness and social isolation. American Sociological Review, 38(3), 311-326.

Hernández-Anzora, M. (2017). Discusión sobre la incidencia política de las pandillas. En Hernández-Anzora, M. (ed.), ¿Hemos perdido el combate contra las maras? (pp. 279-322). San Salvador: Fundación Friedrich Ebert.

Hernández-Sampieri, R., Fernández-Collado, C. y Baptista Lucio, P. (2006). Metodología de la investigación ( $\left.4^{\mathrm{a}} \mathrm{ed}\right)$. México: McGraw-Hill Interamericana.

Hövermann, A., Groß E. M, Zick, A. and Messner, S. F (2015). Understanding the devaluation of vulnerable groups: A novel application of Institutional Anomie Theory. Social Science Research, 52, 408-421. Doi: 10.1016/j.ssresearch.2015.03.001

Instituto Universitario de Opinión Pública [Iudop] (2014). La situación de la seguridad y de la justicia 2009-2014. Entre expectativas de cambio, mano dura militar y treguas. San Salvador: Autor.

Latinobarómetro (2017). Informe Latinobarómetro 2017. Recuperado de http://www.latinobarometro.org/latNewsShow.jsp.

Legge, S., Davidov, E. and Schmidt, P. (2008). Social structural effects on the level and development of the individual experience of anomie in the German population. International Journal of Conflict and Violence (IJCV), 2(2), 248-267. Doi: 10.4119/UNIBI/ijcv.39

Lytkina, E. (2015). Anomie And Alienation In The Post-Communist Area: A Reapplication Of The Middleton Scale In Russia And Kazakhstan. Working Papers, NRU Higher School of Economics. Retrieved from https://www.hse.ru/data/2015/02/20/1090834924/32PSY2015.pdf. 
Revista Iberoamericana

de las Ciencias Sociales y

Humanísticas

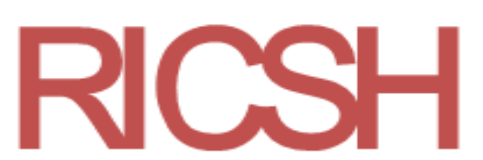

ISSN: 2395 - 7972

McClosky, H. and Schaar, J. H (1965a). Anomy: Reply to Srole and Nettler. American Sociological Review, 30(5), 763-767.

McClosky, H. and Schaar, J. H. (1965b). Psychological dimensions of anomy. American Sociological Review, 30(1), 14-40.

Mc Evoy, C. and Hideg, G. (2017). Global violent deaths 2017. Time to decide. Retrieved from https://www.smallarmssurvey.org/fileadmin/docs/U-Reports/SAS-Report-GVD2017.pdf.

Merton, R. (1964). Teoría y estructura sociales. México: Fondo de Cultura Económica

Messner, S. and Rosenfeld, R. (2007). Crime and the American Dream (4 ${ }^{\text {th }}$ ed.). Belmont: Wadsworth.

Messner, S., Thome, H. and Rosenfeld, R. (2008). Institutions, anomie, and violent crime: Clarifying and elaborating institutional-anomie theory. International Journal of Conflict and Violence (IJCV), 2(2), 163-181. Doi: 10.4119/UNIBI/ijcv.35

Montero, J. R., Gunther, R. y Torcal, M. (1998). Actitudes hacia la democracia en España: legitimidad, descontento y desafección. REIS, 83, 9-49. Doi: 10.2307/40184120

Muratori, M., Delfino, G. I., y Zubieta, E.M. (2013). Percepción de anomia, confianza y bienestar: la mirada desde la psicología social. Revista de Psicología (PUCP), 31(1), 129-150.

Nachmias, D (1974). Modes and types of political alienation. The British Journal of Sociology, 25(4), 478-493. Doi: 10.2307/590156

Nisbet, R. (1977). La formación del pensamiento sociológico I y II. Buenos Aires: Amorrortu Editores.

Orellana, C. I. (2012). Exclusión, crisis del mundo del trabajo y precariedad: A vueltas con el tema de la ciudadanía. Estudios Centroamericanos (ECA), 67(729), 229-258.

Orellana, C. I. (2018a). El autoritarismo de derechas como sustrato psicosocial de odio. Teoría y Praxis, 32, 105-136. Doi: 10.5377/typ.v0i32.6392

Orellana, C. I. (2018b). Propiedades métricas de la Escala Salvadoreña de Autoritarismo de Derechas (RWA). Revista Evaluar, 18(1), 12-26. Recuperado de https://revistas.unc.edu.ar/index.php/revaluar/article/view/19766.

Passas, N. (1997). Anomie, Reference Groups and Relative Deprivation. In Passas, N. y Agnew, R. (eds.), The future of the anomie theory (pp. 62-94). Boston: Northeastern University Press.

Programa Estado de la Nación [PEN] (2016). Quinto informe. Estado de la región en desarrollo humano sostenible. San José: Autor. 


\section{Revista Iberoamericana}

de las Ciencias Sociales y

Humanísticas

ISSN: $2395-7972$

Programa de las Naciones Unidas para el Desarrollo [PNUD] (2009). Informe sobre desarrollo humano para América Central 2009-2010. Abrir espacios a la seguridad ciudadana y el desarrollo humano. San Salvador: Autor.

Programa de las Naciones Unidas para el Desarrollo [PNUD] (2013). Informe sobre Desarrollo humano El Salvador 2013. Imaginar un nuevo país. Hacerlo posible. San Salvador: Autor. Recuperado de 1http://www.sv.undp.org/content/el_salvador/es/home.html.

Programa de las Naciones Unidas para el Desarrollo [PNUD] (2018). Informe sobre desarrollo humano El Salvador 2018. ¡Soy joven! ¿Y ahora qué? San Salvador: Autor. Recuperado de: http://www.sv.undp.org/content/dam/el_salvador/docs/IDHES\%202018\%20WEB.pdf.

Rodríguez, J. M. (2006). Análisis comparativo de confiabilidad y validez de dos escalas de anomia. Revista Interamericana de Psicología (RIP,) 40(2), 193-204

Schoepfer, A. (2015). Institutional Anomie Theory. In Jennings, W. G. (ed.), The encyclopedia of crime and punishmen. Wiley Online Library. Retrieved from https://onlinelibrary.wiley.com/doi/full/10.1002/9781118519639.wbecpx026.

Seeman, M. (1983). Alienation motifs in contemporary theorizing: The hidden continuity of the classic themes. Social Psychology Quarterly, 46(3), 171-184. Doi: 10.2307/3033789.

Seeman, M. (1991). Alienation and Anomie. In Robinson, J. P., Shaver, P. R. and Wrightsman, L. S. (eds.), Measures of personality and social psychological attitudes (pp. 291-372). San Diego: Academic Press.

Smith, H. P. and Bohm R. M. (2008). Beyond anomie: Alienation and crime. Critical Criminology, $16(1), 1-15$.

Srole, L. (1956). Social Integration and Certain Corollaries: An Exploratory Study. American Sociological Review, 21(6), 709-716. Doi:10.2307/2088422.

Srole, L. (1965). A Comment on "Anomy". American Sociological Review, 30(5), 757-762. Doi: $10.2307 / 2091143$.

Taber, K. S. (2017). The use of Cronbach's alpha when developing and reporting research instruments in science education. Research in Science Education, 1-24. Doi: $10.1007 / \mathrm{s} 11165-016-9602-2$

Teymoori, A., Jetten, J., Bastian, B., Ariyanto, A., Autin, F., Ayub, N., Badea, C., Besta, T., Butera, F., Costa-Lopes, R., Cui, L., Fantini, C., Finchilescu, G., Gaertner, L., Gollwitzer, M., Gómez, Á., González, R., Hong, Y., Jensen, D., Karasawa, M., Kessler, T., Klein, O., Lima, M., Mähönen, T., Megevand, L., Morton, T., Paladino, P., Polya, T., Ruza, 
Revista Iberoamericana

de las Ciencias Sociales y

Humanísticas

ISSN: $2395-7972$

A., Shahrazad, W., Sharma, S., Torres, A., van der Bles, A. and Wohl, M. (2016). Revisiting the measurement of anomie. PloS ONE, 11(7), 1-27. Doi: 10.1371/journal.pone.0158370

Teymoori, A., Bastian, B. and Jetten, J. (2017). Towards a Psychological Analysis of Anomie. Political Psychology, 38(6), 1009-1023. Doi: 10.1111/pops.12377

Vera Noriega, J. Á., Bautista, G., Ramírez, M. y Yáñez, A. I. (2012). Relación entre anomia social, alienación y conducta antisocial en jóvenes infractores mexicanos. Revista Latinoamericana de Ciencias Sociales, Niñez y Juventud, 10(2), 943-955. Recuperado de https://dialnet.unirioja.es/servlet/articulo?codigo $=4023716$.

Walter, K. (2018). La muerte violenta como realidad cotidiana: El Salvador, 1912-2016. San Salvador: AccesArte. 